\title{
VIVÊNCIAS EM ARTE E NATUREZA NA INFÂNCIA E SUAS REPERCUSSÕES NA VIDA ADULTA
}

\author{
EXPERIENCIA CON EL ARTE Y LA NATUREZA EN LA NIÑEZ Y SUS \\ REPERCUSIONES EN LA VIDA ADULTA
}

\section{LIVING ON ART AND NATURE IN CHILDREN AND THEIR REPERCUSSIONS IN ADULT LIFE}

\author{
Denise HADDAD ${ }^{1}$ \\ Janaina Florinda Ferri CINTRÃO ${ }^{2}$
}

RESUMO: Esta pesquisa refere-se à recuperação de uma trajetória vivenciada pelas crianças que frequentaram a "Aldeia Recreação Infantil" nos anos de 1980 a 1986 em Araraquara- SP, a fim de identificar a importância das práticas integradas à natureza, tais como o ciclo alimentar, a arte criativa, o respeito ao brincar e o convívio com a comunidade escolar, ao proporcionar referências e valores em suas vidas adultas. Para tanto, utilizou-se da Historia Oral, a partir de narrativas desses ex-alunos que, na época em que estudaram nessa escola, se encontravam na faixa etária entre 2 a 6 anos. Foram recolhidos depoimentos de suas memórias significativas que trouxeram base para uma análise e referências de princípios e valores repercutidos na sua vida adulta. Percebe-se que apesar das experiências deste grupo terem se dado em tão tenra idade, elas permaneceram vivas, posto que impressas na memória corporal por eles registrada, sendo, portanto, de ordem sensorial e não mental e/ou intelectual.

PALAVRAS-CHAVE: Arte e natureza. Educação infantil. Memória. Brincar. Corpo.

RESUMEN: Esta investigación se refiere a la recuperación de trayectorias de experiencias de vida de niños que frecuentaron la escuela "Aldeia Recreação Infantil", desde los años de 1980 a 1986, en Araraquara - SP, con el objetivo de identificar la importancia de las prácticas integradas a la naturaliza que fueron llevadas a cabo en la escuela, tales como el ciclo alimentario, arte creativo, respecto al acto de jugar y al convivio con la comunidade de la escuela, factores estos que proporcionaron referencias y valores personales y culturares en las vidas de los niños cuando adultos.

${ }^{1}$ Universidade de Araraquara (UNIARA), Araraquara - SP - Brasil. Mestre em Desenvolvimento Territorial e Meio Ambiente pela Universidade de Araraquara (UNIARA), 2018. Especialização em Educação Ambiental pela Faculdade de Saúde Pública da Universidade de São Paulo (USP), em 2000 e em Ecologia, Arte e Sustentabilidade pela Universidade Estadual Paulista (UNESP) e Universidade Aberta do Meio Ambiente e da Cultura de Paz (UMAPAZ), em 2011. ORCID: <https://orcid.org/00000001-7053-0881>. E-mail: naturezaviva9@gmail.com

${ }^{2}$ Universidade de Araraquara (UNIARA), Araraquara - SP - Brasil. Mestre em Desenvolvimento Territorial e Meio Ambiente pela Universidade de Araraquara (UNIARA), 2018. Especialização em Educação Ambiental pela Faculdade de Saúde Pública da Universidade de São Paulo (USP), em 2000 e em Ecologia, Arte e Sustentabilidade pela Universidade Estadual Paulista (UNESP) e Universidade Aberta do Meio Ambiente e da Cultura de Paz (UMAPAZ), em 2011. E-mail: jcintrao.mestrado@uniara.com.br 
Para ello, se tomó como referencia la Historia Oral, a partir de narrativas de esos exalumnos que, en la referida época se encontraban con edad entre 2 a 6 años. Fueron selecionados relatos de memorias significativos que disponibilizaron indicios para el análisis y referencias de principios y valores que repercutieron en sus vidas adultas. Se puede percibir por el análisis realizado que aunque las experiencias de este grupo hayan ocorrido en tan temprana edad, ellas todavía permanecieron vivas, expresadas en las narrativas sobre su memoria corporal registradas por ellos, quizá justamente por ser de ordem sensorial y no mental y/o intelectual.

PALABRAS CLAVE: Arte y naturaleza. Educación infantil. Memoria. Jugar. Cuerpo.

ABSTRACT: This research refers to recover the trajectory experienced by the children who attended the "Aldeia Recreação Infantil" from 1980 to 1986 in Araraquara-SP, in order to identify the importance of practices integrated with nature, such as cultivation and elaboration of food, contact with animals, creative art, respect with others when playing and coexistence with the school community, provided personal and cultural references and values in their adult lives. For that purpose, Oral History was used, based on narratives of these ex-students, who were between 2 and 6 years old at that time. Testimonies were collected from their significant memories that brought the basis for an analysis and references of principles and values reflected in their adult life. It is perceived that although the experiences of this group were given at such a young age, they remained alive, since they are imprinted in their corporeal memory and being sensorial not mental and / or intellectual.

KEYWORDS: Art and nature. Child education. Memory. Oral History.

\section{Introdução}

A escola “Aldeia Recreação Infantil” foi fundada em 1980 e nasceu do desejo de oferecer uma vivência educativa ampla, inovadora e diferenciada para crianças de Araraquara, no interior do Estado de São Paulo. Instalada num local privilegiado, com extensa área verde, ela propiciou o desenvolvimento de atividades com hortas, animais, jardinagem, culinária e teatro. Tratava-se de uma ação educacional de vanguarda, numa época em que a ideia de práticas sustentáveis na Educação não era contemplada pelo currículo escolar. Estimulava-se o contato direto das crianças com os elementos da natureza, tais como os ciclos, as estações, as plantas, o solo, a água, os alimentos, os animais, e desenvolviam-se atividades que incluíam todo um sistema integrado de vivências práticas da vida, além de criar conexões entre a criança e a terra.

Quando a "Aldeia Recreação Infantil” foi criada, não existiam muitas referências teóricas sobre a organização de uma escola infantil que valorizasse a infância e rompesse os padrões do sistema escolar vigente. Muitas escolas alternativas baseadas na 
prática foram criadas com esse intuito e a escola "Aldeia Recreação Infantil" foi uma delas.

A metodologia de ensino era aplicada de modo intuitivo e construída a partir do aproveitamento das metodologias educacionais contemporâneas naquilo que se entendia adequado ao novo modelo educacional que a escola pretendia. Não havia métodos específicos, pois, se tratava, antes de tudo, da criação de um espaço aberto para a construção conjunta com os educadores e os pais e, portanto, suas práticas estavam sujeitas a uma constante reavaliação.

Nela, a criança era respeitada em sua liberdade de expressão e a sua individualidade era valorizada em todas suas manifestações. Valia-se de todo e qualquer material expressivo que não delimitasse a comunicação, mantendo a criança livre para usufruir de todo seu potencial criativo. Todos os desenhos e expressões artísticas eram inspirados pelas próprias crianças e cabia ao professor, como observador, incentivá-los, para que sua criação ganhasse forma e vida.

A escola oferecia um espaço diversificado composto de salas temáticas como música, artes, casinha de boneca, cozinha experimental, jogos criativos e oficina de criação. Oferecia, também, extensa área verde propiciando o desenvolvimento de atividades com hortas, animais, jardinagem, culinária e artes. Primava pelo respeito ao desenvolvimento integral da criança, sua individualidade e liberdade de expressão. A criança era livre para expressar e expandir seu potencial criativo e a família era uma integrante efetiva desse contexto.

Segundo Richard Louv (2016), os ambientes naturais são essenciais para um desenvolvimento saudável da criança porque estimulam todos os sentidos e integram a brincadeira à aprendizagem. Experiências multissensoriais em ambientes naturais ajudam a desenvolver estruturas cognitivas necessárias para um desenvolvimento intelectual.

A experiência sensível, aliada aos usos e percepção cultural dos seres do meio ambiente, traz novos significados como as plantas, animais, céu, terra, pensando em um conjunto de múltiplas inter-relações sistêmico, como diz Capra (2006), que envolvem saberes, técnicas e uma constante interpenetração intelectual e prática entre a natureza e a sociedade. Esses atributos fazem com que a natureza não seja algo estático, mas esteja em permanente movimento cósmico. 
A natureza inspira a criatividade da criança, demandando a percepção e o amplo uso dos sentidos. No jardim, aprendemos sobre os ciclos dos alimentos, um dos mais antigos e mais importantes conceitos ecológicos. Desde o início da ciência ecológica, os ecologistas vêm estudando os relacionamentos da alimentação. Inicialmente, formularam o conceito da cadeia alimentar, usada ainda hoje; ou seja, pequenas criaturas devoradas por outras grandes, as quais, a seu turno, são devoradas por outras ainda maiores e assim por diante. Depois, os ecologistas compreenderam que, ao morrer, todas as grandes criaturas são devoradas por minúsculas outras, que são chamadas organismos de decomposição. Isto levou ao conceito dos ciclos alimentares. Finalmente, reconheceram a existência de uma interconexão entre todos esses ciclos alimentares, uma vez que muitas espécies se alimentam de diversas outras e, assim, os ciclos alimentares tornam-se parte de uma rede interconectada. Portanto, o conceito ecológico contemporâneo é o da teia alimentar, uma rede de relacionamentos englobando a alimentação (CAPRA, 2006 p. 88).

A criança em sua tenra idade está com todos seus sentidos muito abertos para o mundo que ela vai descobrir. Em um ambiente natural, a criança está cercada de estímulos que proporcionam a descoberta do mundo enquanto se descobrem.

A escola "Aldeia Recreação Infantil" sempre deu muita importância ao brincar livre, tanto no tanque de areia quanto nas brincadeiras imaginárias, como as embaixo das árvores, as cabanas para os animais, os balanços, os pneus, as corridas no campo de futebol, no parquinho, no jardim, na horta Aos professores e educadores cabiam incentivá-las, sem interferir na liberdade e criatividade espontânea inata nesta fase de desenvolvimento. Brincar, para a criança, implica muito mais que a própria ação. Durante o ato de brincar pode-se conhecer a criança, suas emoções, a maneira como ela interage com seus colegas, seu desempenho físico-motor, seu estágio de desenvolvimento, seu nível linguístico e sua formação moral.

Para que educar? Para recuperar essa harmonia fundamental que não destrói, que não explora, que não abusa, que não pretende dominar o mundo natural, mas que deseja conhecê-lo na aceitação e respeito para que o bem-estar humano se dê no bem-estar da natureza em que se vive. Para isso é preciso aprender a olhar e escutar sem medo de deixar de ser, sem medo de deixar o outro ser em harmonia, sem submissão. Quero um mundo em que respeitemos o mundo natural que nos sustenta, um mundo no qual se devolva o que se toma emprestado da natureza para viver. Ao sermos seres vivos, somos seres autônomos, no viver não o somos (MATURANA, 2002, p. 34$35)$.

A criança aprende pela ação com sentido que emerge de sua natureza intrínseca e essa reverberação parte da proximidade com ambientes naturais em que todos os elementos aguçam sua curiosidade, permitem a ação espontânea de sua criatividade e 
promovem desafios constantes que requer emoção, ação, interação e autoconhecimento (CAPRA, 2006).

A “Aldeia Recreação Infantil” primava por permitir que a criança se expressasse livremente em suas diferentes linguagens, proporcionando espaços de acesso ao brincar livre, respeitando o tempo, as escolhas e ampliando as possibilidades de criação das crianças. As experiências lúdicas pressupõem a não obrigatoriedade, a liberdade de expressão de seus desejos, a necessidade de tempos alongados e não fragmentados, o convívio espontâneo entre pessoas, objetos e equipamentos que não imprimam uma resposta única preestabelecida. Um lugar de sensibilização do olhar para as belezas produzidas diariamente pelas crianças, sendo ela a própria geradora de conteúdos e brincadeiras.

Atividades com o ciclo alimentar na infância permitem o acesso a esta cadeia de ciclos, o cuidar, a transformação, além da consciência de que pra tudo existe o tempo de maturar. Assim, nada vem pronto, é preciso o cuidar. Esta simples ação reproduz um significado existencial maior do que podemos imaginar. Evidencia o brincar como uma expressão marcante e indissociável da infância, que pode ser desenvolvido em meio à natureza, com poucos recursos e em relação constante com os pares.

\begin{abstract}
A natureza trás em si desafios físicos e estéticos que mobilizam as crianças a se aventurar. A lama, a areia as pedras, seus formatos e cores, seus pesos, temperaturas; as plantas, suas folhas, sementes, troncos e talos, raízes com diferentes texturas, cheiros, cores e tamanhos; e os animais que habitam esses lugares: os insetos com seus ruídos peculiares, suas cores e formatos; os diferentes relevos, as topografias: rios montes, barrancos, planícies. Enfim, um universo de possibilidades a serem observadas e investigadas, a serem brincadas, que nos levam ao sentimento comunhão. Somos parte da natureza, e podemos e devemos nos religar a ela (BARBIERI, 2012, p. 116).
\end{abstract}

Em meio à natureza, as crianças podem ser surpreendidas pelas possibilidades que o espaço natural oferece, e ainda favorece a estimulação dos sentidos como o olfato, tato, paladar, visão e audição, o contato com os quatro elementos da natureza - terra, fogo, água e ar -, a aproximação com a fauna e a flora local, a exploração das capacidades e habilidades motoras, tal como subir em árvores, cavando, escalando, correndo, etc..., exercícios para a autonomia e socialização.

Na natureza, as crianças são solicitadas a agir de dentro para fora, pois há apenas sugestões do que, como e por que fazer algo. Ao contrário dos brinquedos prontos, ou da televisão, que já possuem forma, função e conteúdos definidos, os elementos da natureza convidam a 
criança a agir ativamente no mundo, transformando a matéria a partir de sua imaginação e ação. Assim, de um tronco nasce um carrinho; de um sabugo, uma boneca; de uma folha de bananeira, uma cabana. Ao transformar a matéria-prima, a criança produz cultura (MEIRELLES, 2014, p. 64).

O resgate da memória de vivência da infância pode trazer contributos de várias naturezas, dentre elas, a identificação da essência das experiências que se manifestam pela memória e sua contribuição para pensar a Educação. O presente artigo busca enfatizar a importância de vivências significativas na infância como direcionamento e base de valores na idade adulta e tem por objetivo identificar o quanto as práticas integradas à natureza e à arte criativa de ex-alunos que frequentaram a escola "Aldeia Recreação Infantil”, no período de 1980 a 1986, proporcionaram referências e valores pessoais e culturais em suas vidas adultas.

\section{Procedimentos Metodológicos}

Utilizou-se como recurso metodológico a História Oral. De acordo com Thompson (1992), a História Oral pode ser um meio de transformar tanto o conteúdo quanto a finalidade da história. A reconstrução da história pelos próprios indivíduos torna-se ela mesma um processo de colaboração muito mais amplo e pode adquirir dignidade e sentido de finalidade ao rememorarem a própria vida e fornecerem informações valiosas a uma geração mais jovem.

Depoimentos de adultos que frequentaram a escola "Aldeia Recreação Infantil", quando crianças, revelavam memórias de vivencias positivas e ricas em detalhes com a capacidade de avaliarem criticamente o que passaram e o que de valores permaneceram.

Realizou-se para tanto entrevistas individuais com treze ex-alunos, que frequentaram a escola “Aldeia Recreação Infantil” entre os anos de 1980 a 1986. Citaremos trechos de depoimentos de seis destes depoentes abaixo relacionados:

- Ana Silvia de Moraes, 38 anos, permaneceu na Aldeia por 4 anos entre 1980 a 1984. Cursou Jornalismo, Psicologia e está cursando Doutorado em Educação. É casada, tem uma filha e reside na cidade de São Paulo-SP.

- Claudia Petlik, 38 anos, permaneceu na Aldeia por 4 anos entre 1980 a 1984. Cursou Psicologia, é casada, tem 2 filhos e reside na cidade de São Paulo-SP. 
- Denise Zakaib, 38 anos, permaneceu na Aldeia por 4 anos entre 1980 a 1984. Cursou Arquitetura, é casada, não tem filhos, atua como Educadora em Artes e reside na cidade de Araraquara- SP.

- Luciana Lupo, 37 anos, permaneceu 4 anos entre os anos de 1980 a 1984. Cursou Administração de Empresa, é casada, tem uma filha, Empresária e reside na cidade de Recife-PE.

- Luiza de Miranda Costa Moldan, 39 anos, permaneceu na Aldeia por 4 anos, entre 1981 a 1985. Cursou Fisioterapia, é casada, tem 2 filhos. Atua como Fisioterapeuta, reside na cidade de Araraquara- SP.

- Mariana Gianechchini Ferrari, 37 anos, permaneceu na Aldeia por 4 anos entre os anos de 1980 a 1984. Cursou Psicologia, Especializada em Psicanálise Infantil, é casada, tem dois filhos, atua como Psicanalista Infantil e reside na cidade de Araraquara- SP.

Os depoimentos foram realizados de modo informal, buscando ao máximo um ambiente tranquilo e descontraído com o objetivo de estabelecer uma relação de afinidade entre as partes, para que eles se sentissem à vontade na exposição de suas percepções, sensações, emoções e memórias e, assim, contribuir com dados que oferecessem subsídios à sustentação da hipótese levantada por esta pesquisa. Os depoimentos realizados foram devidamente autorizados pelos depoentes e arquivados.

\section{Memórias que viram História}

Figura 01: Pintando as crianças no palco de teatro

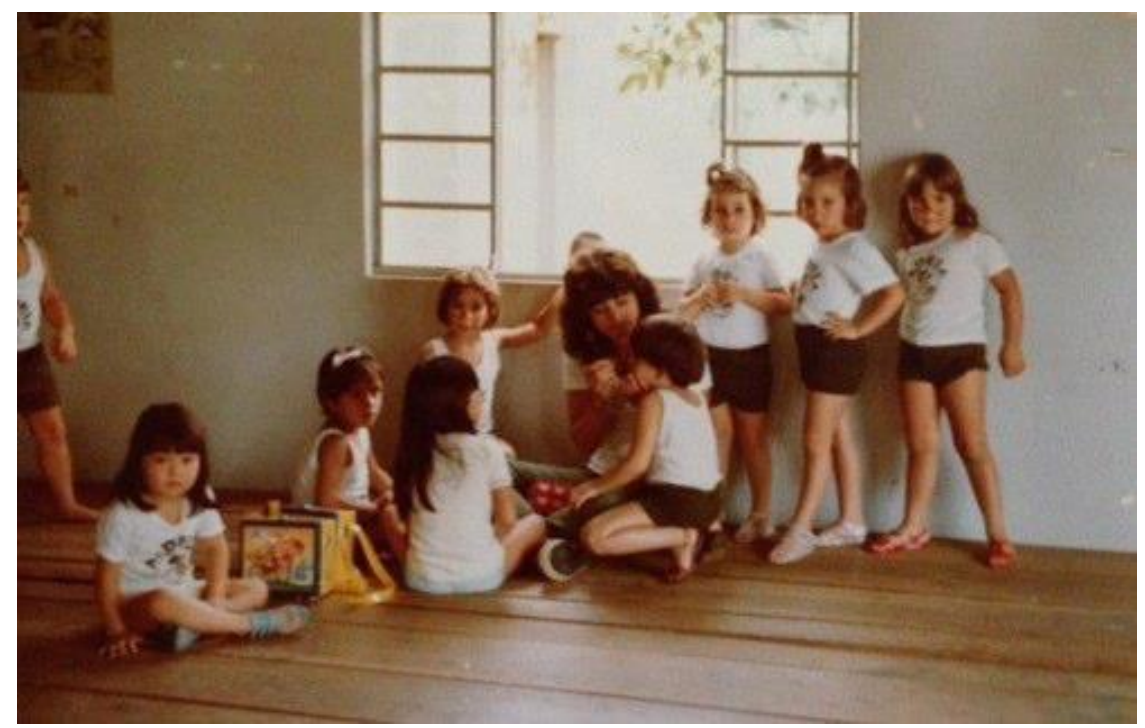

Fonte: As próprias autoras. 
Ao coletar os depoimentos destes meninos e meninas, atualmente adultos, impressiona os detalhes que chegaram repletos de emoções e também a capacidade crítica que permitiu a eles avaliarem o que vivenciaram e o que de valor ficou. Como cita Bosi (1994), a Memória acorda e ressignifica o presente.

Pela memória, o passado não só vem à tona das águas presentes, misturando-se com as percepções imediatas, como também empurra, "desloca" estas últimas, ocupando o espaço todo da consciência. A memória aparece como força subjetiva ao mesmo tempo profunda e ativa, latente e penetrante, oculta e invasora (BOSI, 1994, p. 47).

Este processo de rememoração provocou uma série de reflexões sobre o passado, o presente e o futuro nos depoentes e também possibilitou a reconstrução dos sentidos da experiência vivida a partir da ótica do presente. Uma reavaliação de percurso e do processo de compreensão de suas práticas.

Os depoimentos, por meio das memórias descritas em diferentes perspectivas, justificam o valor das experiências vivenciadas na infância que reverberaram em referencias atuais em suas vidas. Conforme Bobbio,

O relembrar é uma atividade mental que não exercitamos com freqüência por que é desgastante ou embaraçosa. Mas é uma atividade salutar. Na rememoração reencontramos a nós mesmos e a nossa identidade, não obstante muitos anos transcorridos, os mil fatos vividos. [...] Se o futuro se abre para a imaginação, mas não nos pertence mais, o mundo passado é aquele no qual, recorrendo a nossas lembranças, podemos buscar refúgio dentro de nós mesmos, debruçarnos sobre nós mesmos e nele reconstruir nossa identidade (BOBBIO, 1997 p. 30-31).

-Era um lugar muito livre, que deixava a criança muito livre, tinha muitas atividades, mais artísticas... Acho que era uma liberdade que me marcou que eu experimentei e que acho que eu não tivesse outros espaços em que eu vivia isso, naquele momento aquele era um espaço que me dava mais liberdade do que outros que eu tinha. (Ana Silvia de Moraes, 2016 ).

-É isso mesmo acho que respeito e liberdade para se expressar. Porque eu não sentia uma rigidez, mas eu não sentia uma bagunça, sabe quando o negocio é tão rígido que você precisa dar uma liberada pra extravasar, não tinha porque eu acho que a liberdade também estava fluindo junto com a responsabilidade, quando a gente tem que fazer a nossa parte para tudo acontecer, nem sabia que eu tinha tantas memórias, de uma coisa tão remota. Admiro-me de ter tantas memórias, esta fazendo 35anos! (Denise Zakaib, 2016). 
A liberdade foi um tema relevante entre os depoentes. Privilegiando este lugar na memória como um valor permanente, tanto em suas referências quanto no que tange oferecer aos seus filhos sensações como as que puderam vivenciar na infância. $\mathrm{O}$ exercício de ser criança é, pois, o direito mais significativo da criança, que lhe permite Ser em plenitude e liberdade. Neste sentido, segundo Hortélio, "Tendo conhecido o que isto significa, a criança guardará para sempre a lição maior, a experiência mais inteira de Vida, como tesouro e meta de toda sua busca como ser humano". (HORTÉLIO apud CRUZ, 2005, p. 78).

- Aldeia simplesmente dava espaço pra criança poder se desenvolver de um jeito bom pra criança. Ela respeitava o tempo da criança, trabalhar os sentidos, o motor, a natureza. Tudo acontecia naturalmente, era um espaço que respeitava o tempo da criança, quando me lembro, era um espaço muito gostoso, porque a gente ia lá fazer o que a criança gosta de fazer, então tinha essa conexão com o tempo da criança, isso acho que era muito legal. (Luciana Lupo, 2016) (Figura 02)

Figura 02: Escola Aldeia - Crianças brincando no parque (1982)

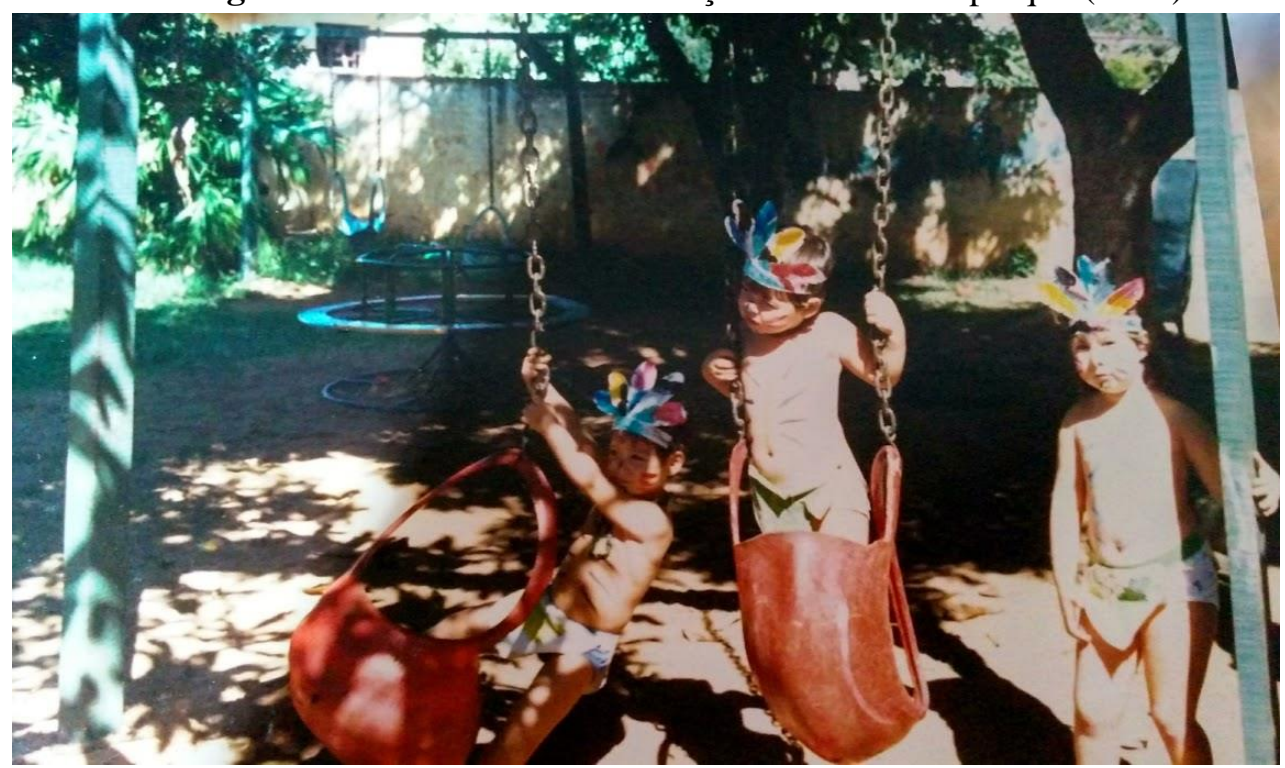

Fonte: As próprias autoras

- Lá a gente não sabia que a gente estava aprendendo, a gente estava achando que estava brincando o tempo todo, não tinha uma coisa que diferenciava o aprender do brincar, este é um valor importante, entender que você pode fazer as coisas sérias importantes da vida, até na vida adulta de uma forma mais leve. (Mariana Ferrari Smirne. 2017).

- A Aldeia me deu este acolhimento, lembro-me de como vocês lidavam com a questão da terra, com a questão do cultivo, eu lembro da cenoura, da gente pegando a cenoura, e eu tenho na 
minha memória, a gente ficava regando, a gente via aquilo crescer .... A culinária prepara a criança pra vida, lembro muito destas atividades (Luisa de Miranda Costa Moldan, 2017).

Como afirma Ferreira-Santos (2012), quando a vivência é inteira, plena de significados, ela permanece viva na memória.

O corpo-memória é o suporte de aferição, de sensibilidade, de ancoragem para estar presente. E é só por meio da experiência vivida pelo corpo e no corpo presente que, mesmo somente por alguns instantes, se possa vivenciar ser Eu mesmo, ser $\mathrm{Eu}$ mesmo inteiro (SANTOS, 2012, p. 101).

A referência ao plantar, ao semear, ao cuidar e ao colher, vivenciada pelo corpo, se expressa de diferentes formas e fica gravada de forma muito peculiar. Essa relação com a terra no contato íntimo com os ciclos, acompanhando o desenvolvimento da semente magicamente se transformar em frutos, que serão, depois, degustados ou transformados e elaborados. Práticas que demarcam um valor que muitos recuperam e reposicionam em suas vidas. (Figura 03)

Figura 03: Arquivo Aldeia - Crianças plantando na horta (1983)

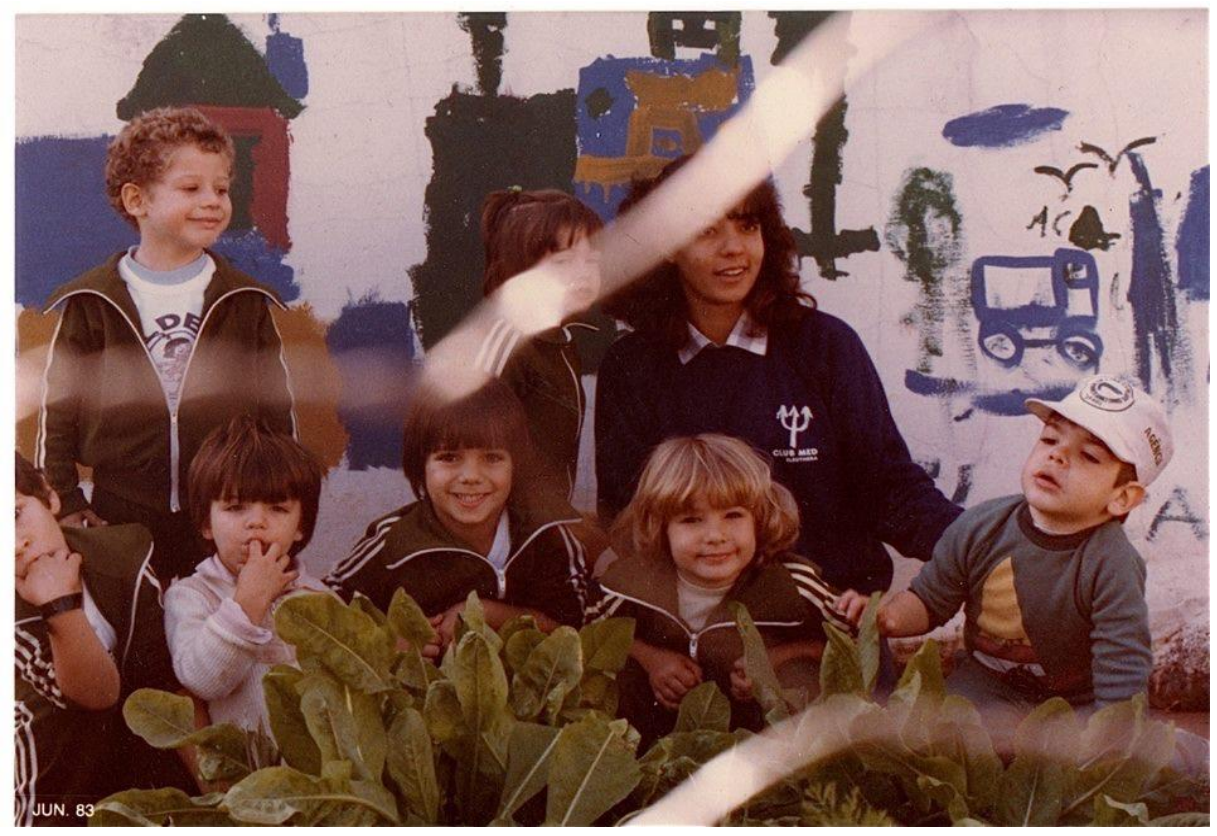

Fonte: As próprias autoras

- A cozinha eu adorava, as receitas que tenho até hoje, tenho muita memória que levamos talvez uma vez por semana pra casa, eu sempre queria fazer em casa. Lembro-me da horta, de plantar, colher, 
tínhamos uma relação ali, não era só que alguém cuidava e a gente estava alheia, lembro-me das coisas da alimentação, a gente cuidava, não era alheio, (Claudia Petlik, 2016)

É perceptível que atividades simples, como plantar, cuidar, colher, cozinhar, foram muito significativas na memória dos depoentes permanecendo como valores que reverberam em suas vidas. Este processo de acompanhar o ciclo alimentar proporcionou um elemento indicativo como referência em suas memórias. É precioso notar que essas práticas trazem uma ressignificação, e o desejo de proporcioná-las as novas gerações.

- A Aldeia trazia estas coisas legais de sucata, de folclore, de fazer pipa, a gente fazia muita culinária, cozinhávamos a mandioca, da horta... Até hoje eu trago esta paixão comigo pela culinária, adoro cozinhar, acho que foi dai. Tenho muitas memórias boas, olhando hoje, do que aprendi quando criança, acho que a melhor coisa que eu tenho é a consciência com a natureza, com os animais, com o meio ambiente, com o mundo, adoro estar no meio do mato. Essas atividades, com certeza tiveram influencia hoje na minha vida, me trouxeram estes valores. (Rodrigo Gatti, 2017)

A Aldeia sempre buscou proporcionar um ambiente harmonioso, ao ajustar a criança ao meio, através da sua própria cultura, diminuindo as possibilidades de conflito, adquirindo solidariedade, cooperação, autoestima e disciplina, exercendo a tolerância dos maiores com os menores, a inclusão de crianças de diferentes classes sociais, de diferentes etnias, comportamentos, experimentando um sentimento que ultrapassasse a consciência coletiva.

- Cada vez que a gente revisita o passado tem um resgate de alguma coisa nova, de uma leitura nova, de um novo olhar, não é estático, reverbera, não tão consciente, recupera sonhos, outro olhar... Este resgate, organizar a memória, verbalizar o que a gente viveu, pra mim foi super importante pra fase de maternidade, porque meus filhos estão nesta fase, de quando eu estava na Aldeia, e toda hora eu pergunto pra eles o que vocês se lembram do ano passado, da escola, porque é legal ir consolidando a memória.. a maioria das pessoas não tem tantas memórias, eu acho legal estimular e a pessoa se conhece assim... Repercute nos valores, o que mais fica, os valores mais recentes. Nas escolhas que eu faço para meus filhos, na maternidade, nas escolhas de música, nas atividades que faço com eles, sempre a base, é o que vivia na Aldeia (Claudia Petlik, 2017).

Vale destacar, que o processo rememorativo pode alterar o futuro do sujeito pesquisado, pois, a memória, além de incomensurável, é mutante e plena de significados de vida, que algumas vezes se confirmam e usualmente se renovam. Segundo Lowenthal, "Toda consciência do passado está fundada na memória. Através das 
lembranças recuperamos consciencia dos acontecimentos anteriores, distinguimos ontem de hoje e confirmamos que já vivemos um passado" (1981, p. 75).

Os depoimentos apontam valores em vários aspectos de suas vivências, sendo difícil restringi-los em uma única vertente. São referências mencionadas que dialogam no olhar sensível ao mundo, numa visão que se adquire a partir de sua base. Princípios que se tornam mais consciente a partir da recuperação de uma trajetória estabelecida e que propicia a partir da rememoração, uma apropriação do que de valor ficou, como afirma Bosi (1994). Pela memória, o passado não só vem à tona das águas presentes, misturando-se com as percepções imediatas, como também empurra, "desloca" estas últimas, ocupando o espaço todo da consciência. A memória aparece como força subjetiva ao mesmo tempo profunda e ativa, latente e penetrante, oculta e invasora (BOSI, 1994, p. 47). Neste mesmo sentido, Nobrega e Mendes (2004) afirmam que

\begin{abstract}
A educação, ao perceber que corpo, natureza e cultura se interpenetram através de uma lógica recursiva, poderá compreender que o corpo natural é cultural, humano e animal, universal e singular, portanto, histórico. Logo, ao perceber que não é possível ir em busca de um corpo isento de história e ao reconhecer a responsabilidade que possui ao colaborar com a reescrita dessa história, ela tem o desafio de permitir desabrochar as subjetividades, abrindo espaços que possibilitem aflorar o ser selvagem, o ser do abismo, um ser que, ao se modificar constantemente, provoca mudanças no ambiente, na sociedade, na cultura. Uma educação que seja capaz de fazer desvendar a capacidade criativa de um corpo que, ao viver, se reestrutura mediante imprevistos, fazendo desvelar a complexa condição humana (NOBREGA, MENDES, 2004, p. 136).
\end{abstract}

\title{
Considerações finais
}

Pode-se citar como pontos relevantes que fundamentaram e direcionaram esta pesquisa como a compreensão do corpo como o veículo do sensível; a natureza como o habitat natural da criança; o brincar como a linguagem da criança; a valorização das linguagens expressivas; a compreensão do ser humano integrado, com aspectos conscientes e inconscientes, que traz a história da humanidade, familiar e pessoal e que nos aponta para o futuro.

Os conceitos que a fundamentaram foram analisados a partir de uma abordagem teórica transversal que, se captados por uma sensibilidade desperta, podem amparar uma nova visão de Educação que tenha como objetivo o desenvolvimento humano e a sustentabilidade da vida. 
Constata-se que, apesar das experiências dos sujeitos dessa pesquisa terem se dado em tão tenra idade, elas permaneceram vivas, posto que impressas na memória corporal por eles registradas e que elas são de ordem sensorial e não mental e/ou intelectual. $\mathrm{O}$ fato de essas vivências terem ocorrido em um curto espaço de tempo e repercutido em suas vidas e nas suas percepções de mundo, influenciando, inclusive, nas suas escolhas profissionais e nas abordagens ideológicas, demonstra o quanto a memória corporal vivenciada na primeira fase da vida é carregada de direcionamentos e fundamentos para o futuro.

É notável também a ênfase de quase todos os depoentes quando afirmam que voltaram a pensar em sua infância quando tiveram filhos e que gostariam de oferecer as mesmas vivências que tiveram. São por esses ciclos que enxergamos as vias da apropriação destes valores.

Conclui-se que as experiências da infância reverberam na idade adulta em diferentes expressões e manifestações de consciência, capazes de ancorar valores essenciais de convívio harmônico com a diversidade através da integração e do aprendizado com a natureza, no caminho da simplicidade, na sensibilidade da escuta e na oportunidade de proporcionar um ambiente de amor, assim como a Mãe Natureza nos proporciona.

\section{REFERÊNCIAS}

BARBIERI, S. Interações: onde está a arte na infância? São Paulo: Blucher, 2012.

BOBBIO, N. O tempo da memória. Rio de Janeiro: Campus, 1997.

BOSI, E. Memória e sociedade: lembranças de velhos. São Paulo: Companhia das Letras, 1994.

CAPRA, F. Alfabetização ecológica: a educação das crianças para um mundo sustentável. São Paulo: Cultrix, 2006.

CRUZ M. C. M.T. Para uma educação da sensibilidade: a experiência da Casa Redonda. Centro de Estudos, 2005, ECA- USP. Disponivel em: <www.teses.usp.br/teses/disponiveis/27/.../AEDUCACAODASENSIBILIDADE.pdf>. Acesso em: 24 set. 2017.

SANTOS, M. F. O ancestral: entre o singular e o universal. In: AMARAL, M. (org.) Culturas Juvenis. São Paulo: FAPESP, 2012. 
LOUV R. A ultima criança na natureza: resgatando nossas crianças do transtorno do défict de natureza. São Paulo: Aquariana 2016.

MATURANA H. Emoções e linguagem na educação e na política. Belo Horizonte: Editora UFMG, 2002.

MEIRELLES, R. (org.) Território do brincar diálogo com escolas. territórios do brincar. 2014. Disponível em: <http://territoriodobrincar.com.br/wpcontent/uploads/2014/02/Territ\%C3\%B3rio_do_Brincar_Di\%C3\%A1logo_com_Escol as-Livro.pdf> . Acesso em: 02 jun. 2017.

NÓBREGA T. P.; MENDES. M.I. B. S. Corpo, natureza e cultura: contribuições para a educação. Revista Brasileira de Educação, n. 27, set./dez., 2004.

THOMPSON, P. A voz do passado: história oral. Rio de Janeiro: Paz e Terra, 1992.

\section{Como referenciar este artigo}

HADDAD, Denise.; CINTRÃO, Janaina Florinda Ferri. Vivências em arte e natureza na infância e suas repercussões na vida adulta. Temas em Educação e Saúde, Araraquara, v.14, n.1, p. 142-155 jan./jun., 2018. E-ISSN: 2526-3471. DOI: 10.26673/rtes.v14.n1.2018.11276

Submetido em: 05/02/2018

Aprovado em: 05/05/2018 